\title{
Integration As the Rationale, Diversification As the Orientation: Research on the Driving Force of the Integrated Development of Sports Tourism and Industrial Construction
}

\author{
Kewei $\mathrm{Yu}^{1, *}$, Jingjing $\mathrm{Chen}^{2}$, and Ting Yuan ${ }^{1}$ \\ ${ }^{1}$ Department of Physical Education, Xinhua College of Sun Yat-sen University \\ ${ }^{2}$ School of Health, Xinhua College of Sun Yat-sen University
}

\begin{abstract}
The deep integration and integrated development of sports tourism is the core manifestation of broadening the mass consumption space, increasing mass consumption options, and promoting industrial transformation and upgrading. It is also the key choice for integrating high-quality resources and creating a composite industrial form. Under the promotion of Healthy China, sports tourism with multiple functions such as fitness and self-cultivation and health preservation needs to use industrial integration as the mechanism and diversified development as the direction to create a new pattern of in-depth integration of "sports + tourism", and continue to explore broader Development extension. The article takes sports tourism as the research object, discusses its integrated development dynamics and practical difficulties, and puts forward industrial construction suggestions.
\end{abstract}

\section{Introduction}

On September 4, 2019, the General Office of the State Council issued a special opinion on promoting the highquality development of the sports industry (Guobanfa [2019] No. 43), which pointed out that it is necessary to build a carrier for the development of the sports industry based on the "Sports + " action, consolidate the industrial foundation and encourage the integrated development of sports and tourism ${ }^{[1]}$. Driven by multiple factors such as policy guidelines and public demand, by incorporating the multiple advantages of sports resources, introducing market forces to participate, scientifically deconstructing and rationally restructuring the sports industry, it has enriched the development form of the sports industry, expanded the scale of the sports industry, and fully stimulated sports. The vitality of the tourism market meets the diversified and hierarchical sports tourism consumption enthusiasm of the masses, and promotes the integration and integration of sports tourism and mass consumption demands.

\section{Multiple driving forces for the integrated development of sports tourism}

Sports tourism is the result of the integration and development of a series of factors based on the diverse consumer demands of the masses, smart technology, and innovative ideas. In the national fitness environment,

by basing on the advantage of sports tourism resources, driving the integration and penetration of the elements of the sports tourism industry, enriching the content of sports, optimizing the tourism ecological environment, creating brand-powered and competitive sports tourism projects, and building "sports + tourism" The large-scale industry structure has comprehensively enhanced the development momentum of sports tourism integration.

\subsection{Internal driving force: Cross-industry integration provides new momentum}

As the "Internet $+"$ economy continues to mature, the industrial boundary between sports and tourism is becoming increasingly blurred, and sports tourism continues to deepen and integrate development, gradually forming a new industrial format. First, from the perspective of cross-industry integration, to promote the transformation and development of the tourism industry, it is necessary to fully integrate sports genes. To achieve the leapfrog development of the sports industry, the tourism industry must also be used as a "breakthrough point." Various resources such as sports events, national sports culture, leisure and fitness, and sports facilities have the advantages of "tourism" development. By developing them into attractive and brand-influenced tourism products and projects, it provides the integrated development of sports tourism. The inner foundation. Second, from the perspective of industrial upgrading, my country' $\mathrm{s}$ tourism industry is currently facing real problems such as serious homogeneity and insufficient participation. The "implantation" of sports elements will increase the interaction between tourists and tourist

\footnotetext{
"Corresponding author: 564811521@qq.com
} 
destinations, and improve the stickiness of tourists. Provide an important choice to promote the transformation and optimization of the tourism industry. Third, from the perspective of the value of industrial integration, in the face of a new consumption environment, through the use of sports resources as the basis and tourism services as the platform to promote the integrated development of sports tourism from multiple levels such as the introduction of smart technology, the development of new markets, and the integration of businesses. The new industrial value chain provides a new era power and industrial momentum for the high-speed and high-quality development of sports tourism ${ }^{[2]}$

\subsection{External driving force: the sound development of sports tourism provides new impetus}

As the concept of mass consumption continues to mature, the current tourism industry has entered a new era of leisure tourism. First of all, enrich tourism elements and condense the joint force of industrial development. Under the background of "sports tourism +" deep integration, through exerting the influence of sports activities and social attention, constructing a sports tourism "consumption chain" that includes multiple functions such as event entertainment, accommodation and catering, and forming a full range from "resources to services" The chain system provides a good foundation for the deep integration and leapfrog development of the industrial economy. Secondly, sports tourism is a brandnew form that currently promotes the development of "sports+" and "industry+", and it is also an important choice for enhancing the added value of the tourism industry. By taking "integration and innovation" as the development guide, focus on shaping high-quality sports tourism projects, make up for the shortcomings of infrastructure, cultivate market-oriented brands, build a sports tourism "symbiosis", comprehensively enhance the market recognition of sports tourism projects, and expand integrated development Space, comprehensively enhance the effectiveness of sports tourism integrated development ${ }^{[3]}$. Finally, sports tourism is an industrial form that conveys multiple functional characteristics such as health and wellness. Through the industrial integration effect of "sports + tourism", it will promote the overall development of the tourism industry in the direction of high quality and high efficiency. The supply of traditional tourism products and services mostly stays in a shallow "appreciation" state, and it is difficult to effectively satisfy the public's deep participation experience. Therefore, relying on sports projects and the development of tourism as a breakthrough, it will promote the integrated development of market capital and industrial factors, and provide a new impetus for the sound development of sports tourism.

\subsection{Core pulling power: the diverse needs of the public provide new expectations}

Sports tourism conveys the life characteristics of health, vitality, and fun experience, and fully meets the consumer's demand for health and wellness. Therefore, promoting the cross-border integration of sports tourism has become an important manifestation of satisfying the public's high-quality experience and participation demands. First, in the context of the continuous upgrading of mass consumption structure, my country's tourism industry has entered a golden stage of rapid development. In the face of the era of holistic tourism, through the creation of a new composite industry form, the in-depth integration of sports tourism and the development of "National Fitness" and "Global Tourism" in the same direction have fully satisfied the public's understanding of humanity, nature, and ecological fashion. Consumer demand. Second, sports tourism is a high-level, integrated form of industrial expression. Its core elements are routes with distinctive sports tourism characteristics, sports cultural tourism activities and related cultural and creative products. In the era of increasing public consumption power and increasingly diversified consumer demands, fully integrate public participation experience, optimize sports tourism route planning schemes, innovate sports tourism product design concepts, and give sports tourism projects the necessary differentiation and individual characteristics. It provides consumers with a deeply engaged and unique travel consumption experience ${ }^{[4]}$. Third, sports tourism is a vivid presentation of mass consumption upgrades, and it is also an important direction for promoting the optimization of the sports industry structure and cross-border upgrades. The vigorous development of sports tourism will effectively revitalize sports resources, broaden the space for public consumption, fully adapt to the public's new consumption expectations for health, leisure and sports competition, and provide a new direction for the sports industry to speed up, improve quality, and increase revenue and efficiency. Taking ice and snow sports as an example, driven by the environment of the "Winter Olympic Games 2022", the relevant regions use the "ice and snow economy" as the carrier to develop ice and snow tourism products and create ice and snow sports tourism projects, providing a core driving force for the integrated development of sports tourism.

\section{Diversified difficulties in the integrated development of sports tourism}

Driven by the rich and diverse consumer demand for health and wellness, traditional sports tourism is iteratively upgraded and continues to exert efforts. New sports tourism is integrated and upgraded, with constant innovation, and "sports + tourism" is gradually entering a good state of integration. Sports tourism can meet the diverse expectations of the public for a higher quality of life and better quality of life, and it also provides a new path for industry cross-border integration. However, my country's sports tourism is still in the "shallow level" stage of industrial integration development. The lack of linkage and integration between the two has caused the development of sports tourism to be difficult. 


\subsection{Resource dimension: insufficient cross- industry integration and lack of innovative ideas}

In the current process of integrated development of sports tourism, the lack of effective integration of industrial resources has affected the effectiveness of integrated development of sports tourism. First, the failure to accurately explore cross-industry integration points has affected the effectiveness of the use of sports tourism resources. When developing sports tourism in some areas, they are still stuck in a simple accumulation of resources, failing to fully tap the characteristic advantages of related resources, resulting in "extensive" development of sports tourism projects and affecting the effectiveness of integration. Second, the lack of creative transformation and aesthetic upgrading in resource utilization restricts the level of utilization of sports tourism resources. When promoting the integrated development of sports tourism, it failed to start from the perspective of creativity and innovation, and blindly followed the trend, which affected the sound development of sports tourism. For example, cities blindly launch "urban marathons", lacking good innovations, and failing to meet the public's diversified sports tourism consumption expectations. The third is the lack of a good level of resource development and integration capabilities, and a lack of high-quality and characteristic sports tourism projects. At present, most subjects participating in the development of sports tourism resources and projects generally lack a good sense of innovation and resource integration capabilities, and it is difficult to develop and create high-quality sports tourism projects.

\subsection{Industry dimension: insufficient coordination and lack of sound mechanism}

The integration and development of sports tourism involves multiple industries and multiple fields, and the coordination is difficult and the requirements for collaboration are high. The lack of a sound industrial coordination mechanism at present directly affects the actual effect of the integration and development of sports tourism. On the one hand, sports tourism lacks a clear industry ownership, and there is a lack of effective coordination between industries. The sports industry and the tourism industry belong to different organizations. During the development, the integrated development path of sports tourism was explored from the perspective of a single industry, and the connotation of sports tourism development was not deeply explored. As a result, the collaborative development "floated on the surface" and "flowed in "Form" and other issues. For example, some areas are named as "sports tourism towns", but the development and construction from the perspective of real estate has caused the undesirable phenomenon of "empty cities". On the other hand, the development of sports tourism lacks standardized standards and unified systems, and the development of industry lacks the support of talents and smart technology. At present, the standardization of sports tourism is not perfect, and the supervision mechanism is lacking, causing disorderly construction and blind development of sports tourism projects, and it is difficult to effectively guide the healthy development of sports tourism. At the same time, the current development of sports tourism lacks compound talents who understand management and good planning, which restricts the integration and development process.

\subsection{Model dimension: market integration is not deep, lack of model reconstruction}

In the current process of integrated development of sports tourism, due to the lack of good marketing and promotion models, it directly triggers the integrated development dilemma. First, it lacks a market-oriented marketing model and a benign promotion mechanism. At present, most sports tourism projects carry out marketing in a passive way, and fail to find a suitable marketing model for sports tourism projects. In the promotion of sports tourism projects, the lack of grasp of the law of media integration and the lack of a good promotion mechanism makes it difficult to effectively stimulate the public' $\mathrm{s}$ motivation to participate, which affects the social cognition and brand building of sports tourism projects. Second, the lack of a mature and systematic sports tourism development model. As a brand-new integrated business format, sports tourism puts forward higher requirements for project development and operation mode. At present, sports tourism lacks a clear development direction and high-quality projects, coupled with insufficient investment in innovation, affecting the sound development of sports tourism.

\section{Industrial construction suggestions for the integrated development of sports tourism}

In order to achieve the best results of the integrated development of sports tourism, it is necessary to base on the concept of co-construction and sharing of superior resources, rely on superior sports resources, take the development of tourism projects as the direction, adhere to tourist demand orientation, practice service awareness, and pass relevant The sports projects, resources and products shall be properly transformed into tourism, and the supporting service facilities of sports tourism shall be actively improved, and the marketization and industrialization development level of "sports + tourism" shall be comprehensively improved.

\subsection{Grasp the integration trend and optimize the industry development ecology}

Sports and tourism have a strong industrial relevance. In the national fitness environment, it is necessary to fully grasp the development direction of sports tourism industry upgrading, actively cultivate new industrial integration points and value-added points, and continue to optimize the development ecology of sports tourism industry. First, it is necessary to select the appropriate sports tourism industry format based on the consumption power of consumer groups. Through the development of key 
sports tourism projects such as sports parks, sports events, and sports characteristic towns, the overall development of related industries in the region will be promoted. Second, it is necessary to vigorously develop sports tourism projects, continue to optimize the industry structure, through combing the existing and planned sports tourism business in the region, and comprehensively and meticulously optimize sports tourism projects according to different industry classifications, and scientifically plan and coordinate development. The concept enhances the quality of development. For example, areas that have the conditions for the construction of sports towns should take "sports + tourism" as the theme, give full play to the integration advantages of "sports +", and build sports towns with multiple functions such as tourism and leisure, event display, and sports culture dissemination. Build a good platform for the development of sports tourism by creating a tourism scene with beautiful ecological and green life. Third, we must pay attention to exploring the cultural connotation of characteristic sports projects in the region, enrich sports tourism products and services through innovative use and active display of them, and create an integrated, linked and integrated development of tourism resources network platform, and develop sports resources.Cultural performances, sports intangible cultural heritage project exhibitions, and tourists' full participation in an integrated symbiosis cultural space provide the public with fine-quality and high-quality sports tourism products and services ${ }^{[5]}$.

\subsection{Grasp the integration orientation and improve the industrial development chain}

Sports tourism is a product of cross-border integration of resources. Under the premise of maintaining basic functions, it is necessary to fully tap the elements of leisure, entertainment, sports culture and other elements contained therein, and comprehensively enhance the effectiveness of integrated development by taking advantage of the collaborative development of sports tourism resources. First of all, we must take full participation of the public as the goal orientation, and plan and design sports tourism projects around the actual consumption needs of the public. Through accurate research and judgment on the market demand of sports tourism, clarify the development positioning of related sports tourism projects, continuously optimize the supply and demand structure of sports tourism, and actively develop into multiple related fields such as sports event operation, sports cultural and creative product development, and related equipment manufacturing. Sports tourism industry chain. Secondly, it is necessary to lead the integration process with systematic thinking, by identifying the connection points of the integration and development of sports tourism, introducing creative and innovative concepts, and continuously optimizing the utilization mechanism of sports tourism resources ${ }^{[6]}$. Finally, based on optimizing the sports tourism ecosystem, we must fully grasp the opportunities of the era of national fitness, collect and judge the related motives of the public to participate in sports tourism in advance, accurately excavate and analyze the consumption needs of the public to participate in sports tourism, and develop a scientific and reasonable development setting. Sports tourism projects, continuously improve the supply quality and market recognition of sports tourism projects, and broaden the development space of sports tourism in an all-round way. It is necessary to promote the maturity of the sports tourism industry based on the development concepts of boutique, integration and industrialization. By constructing the development model of "sports tourism + $\mathrm{X}^{\prime \prime}$, the rich and diverse sports resources will be effectively integrated with cultural creativity, aesthetic concepts and other content to create a sports tourism complex that will fully promote the deep integration and integrated development of sports tourism ${ }^{[7]}$.

\subsection{Deepen industrial synergy and stimulate integration vitality}

The key to promoting the integrated development of sports tourism lies in industrial coordination. We should target the shortcomings of the integrated development of sports tourism, eliminate the key factors that hinder integrated development, speed up the rational allocation of market capital, smart technology, and compound talents, and strengthen the sports tourism industry. Development vitality. First, it is necessary to take the application of artificial intelligence and $5 \mathrm{G}$ technology as an opportunity to give full play to the core role of smart technology in promoting the in-depth integration of sports tourism. Through the development and construction of a "smart sports tourism" platform, real-time prediction and prevention of sports tourism risks, and accurate control The popular demand for sports tourism consumption has fully stimulated the vitality of sports tourism elements and improved the level of smart integration of sports tourism. Second, it is necessary to use digital technology as the driving force to create a "sports cloud tourism" that is socially immersive and sports scenes perceptible. By leveraging the advantages of the Internet, multimedia and other platforms, we will promote the integration of offline and online services of sports tourism, effectively satisfying the public's diverse sports tourism consumption demands. In July 2020, Hulunbuir built a "Sports Cloud Tourism" model with the theme of "Sports + Tourism", using 18 platforms including Xinhua News Agency's live cloud, same journey travel, and Douyin to promote the Yakeshi Phoenix Mountain to the public."Winter" crosscountry skiing, Zhalantun Jinlong Mountain "14 Winter" competition venue and other tourist routes provide a new "cloud" channel for sports tourism marketing and promotion. Third, we must take sports events as a breakthrough point, promote the coordinated development of sports events and tourism, and continue to expand the influence and actual value of sports events by shaping event brands. The "Round Greater Bay Area Cycling Race" sponsored by the Guangdong Sports Industry Association, through precise positioning of sports events, in-depth exploration of the local customs, integration of related cities' economy, food, and industry and other resources, has created a sports tourism-based The 
industrial development chain has successfully shaped the mass-dominated sports tourism brand, achieved the integration goal of industrial benefits, brand benefits, and cultural benefits of competitions, and also provided an effective reference for the current integrated development of sports tourism ${ }^{[8]}$

\section{Conclusion}

Under the background of the deep integration of national fitness and global tourism, sports tourism has a broad development space. Facing the consumer demands of public ecology, intelligence, health and leisure, it is of great practical significance to promote the deep integration and efficient development of sports tourism. Based on this, when promoting the integrated development of sports tourism, it is necessary to accurately explore the integration points of the two, by optimizing the supply and demand structure of sports tourism services, supplementing quality supporting services in a timely manner, shaping a new sports tourism value chain, and promoting the high-quality development of sports tourism.

\section{References:}

1. Opinions of the General Office of the State Council on Promoting National Fitness and Sports Consumption to Promote the High-quality Development of the Sports Industry [EB/OL]. The website of the Central People's Government of the People's Republic of China. http://www.gov.cn/gongbao/content/2019/co

ntent 5433722.htm, 2019-09-04/2021-02-03.

2. Yang Qiang. The power and path mechanism of the integrated development of the sports tourism industry[J]. Journal of Physical Education, 2016, (04): 55-62.

3. Xia Hongmin. Promote the development of modern service industry with the spirit of reform and innovation-A preliminary study on the integrated development of culture, tourism, sports, and health in Gansu[J]. Journal of Gansu Administration Institute, 2017, (02): 92-98.

4. Shao Kai; Feng Wenchang. Research on Sports Tourism Conflict under Social Behavior: Structure, Function, and Degree[J]. Regional Research and Development, 2017, (01): 97-102.

5. Wu Qiang. Research on the cultural space of the integration and symbiosis of Chinese traditional national sports cultural resources and tourism resources[J]. Journal of Capital Institute of Physical Education, 2019, (01): 56-60.

6. Sun Yanying. Harmony and Challenge: Research on the Development of Sports Tourism Industry under the Background of "One Belt One Road"[J]. Journal of Xi'an Institute of Sport, 2019, (06):708-711.

7. Li Jinrong; Chen Yuanxin. Innovative strategies to promote sports tourism industry in ethnic areas-
Based on the investigation and thinking of Enshi Tujia and Miao Autonomous Prefecture[J]. Journal of South-Central University for Nationalities (Humanities and Social Sciences Edition), 2020, (03): $140-144$.

8. Xu Li. Research on the coordinated development of sports and tourism under the background of the Guangdong-Hong Kong-Macao Greater Bay Area- Taking the "City Cycling Challenge of the Guangdong-Hong Kong-Macao Greater Bay Area" as an example [J]. Journal of Guangzhou Sport University, 2020, (04): 21-23+47. 